Endocrinol. Japon. 1988, 35 (4), 607-616

\title{
A Case of Hypopituitarism Due to Granulomatous and Lymphocytic Adenohypophysitis with Minimal Pituitary Enlargement: A Possible Variant of Lymphocytic Adenohypophysitis
}

\author{
Masumi MiYAmoto, Hideo SUGAWA, Toru MORI, \\ Nobuo HASHIMOTO AND HIROO IMURA

\begin{abstract}
2nd Division of Internal Medicine and Department of Neurosurgery, Kyoto University School of Medicine,
\end{abstract} \\ 54 Kawaharacho, Shogoin, Sakyoku, Kyoto 606. Japan
}

\begin{abstract}
A 47-year-old woman complaining of cold intolerance, general weaknes and amenorrhea of 10 months duration was diagnosed, by endocrine examinations, as having panhypopituitarism. Skull x-ray films revealed a slightly enlarged sella with double floor sign and MRI showed a low intensity mass in:the pituitary. Transsphenoidal exploration disclosed a degenerated pituitary gland, the histology of which showed a granulomatous lesion with moderate lymphocytic infiltration but containing no multinuclear giant cells. No caseous necrosis, causative microorganisms, or BCG antigen were noted. The present case is considered a variant form of lymphocytic adenohypophysitis.
\end{abstract}

Granulomatous inflammation of the pituitary gland, excluding tuberculosis, syphilis, sarcoidosis and fungal infection, is a rare disorder (Doniach and Wright, 1951; Rickards and Harvey, 1954). Lymphocytic adenohypophysitis is also a rare disorder affecting mainly females and resembling pituitary adenoma because of sellar enlargement. Massive infiltration of lymphocytes is suggestive of its autoimmune nature (Kiaer and Norguard, 1969).

We report here a patient who had hypopituitarism together with a small intrasellar mass discovered through radiological

Received January 19, 1988

Correspondence; Dr. MASUMI MIYAMOTO, 2nd Division of Internal Medicine, Kyoto University School of Medicine, 54-Shogoin, Kawaharacho, Sakyoku, Kyoto 606, Japan imaging, and was diagnosed, by histological examination of the transsphenoidal biopsy specimen, as having granulomatous and lymphocytic adenohypophysitis of unknown etiology.

\section{Case Report}

A 47-year-old woman was admitted to our hospital on March 7th, 1986, because of cold intolerance and general weakness. She delivered a child uneventfully at age 26 , becoming amenorrheic for 5 years after the delivery, but having normal menstrual periods thereafter. Since May 1985, she had had increasing generalized muscular weakness or pain, cold intolerance and amenorrhea. She visited a hospital, and was given a 
prescription of thyroid hormone, with a diagnosis of hypothyroidism. Her symptoms did not improve, however, and she was referred to our hospital.

Physical examination revealed a pale woman with a weight of $55 \mathrm{~kg}$ and height of $158.5 \mathrm{~cm}$. Blood pressure was $132 / 100$ $\mathrm{mmHg}$ and pulse rate was 68 per minute and regular. Axillary temperature was $35.8^{\circ} \mathrm{C}$. Her face appeared pale and

$$
\begin{array}{lccc}
\text { T4 } & 0.8 \sim 1.6 \mu \mathrm{g} / 100 \mathrm{ml} & \text { urinary } 17-\mathrm{OHCS} & 1.0 \sim 1.5 \mathrm{mg} / \text { day } \\
\text { Free T4 } & 0.25 \mathrm{ng} / 100 \mathrm{ml} & 17-\mathrm{KS} & 0.6 \sim 1.2 \mathrm{mg} / \text { day } \\
\text { T3 } & 48 \sim 52 \mathrm{ng} / 100 \mathrm{ml} & \text { Cortisol } & 3.7 \mu \mathrm{g} / 100 \mathrm{~m} \\
\text { TSH } & <0.5 \mu \mathrm{U} / \mathrm{ml} & \text { Estradiol } & 27 \mathrm{pg} / \mathrm{ml}
\end{array}
$$
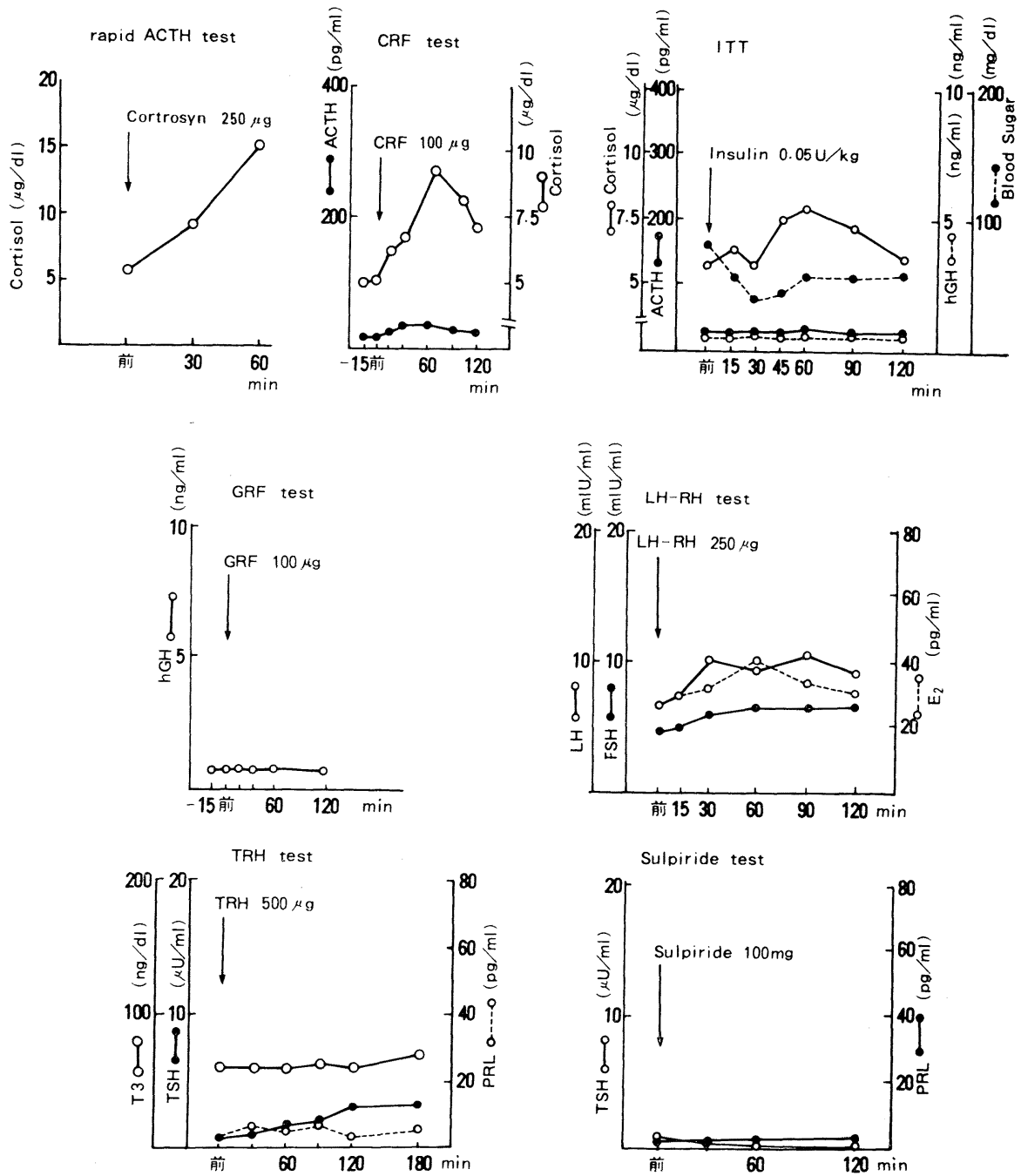

Fig. 1. Anterior pituitary function test results. 
edematous. The thyroid gland was not enlarged. The breasts were not atrophic and no breast discharge was demonstrated. Neurological examination revealed no abnormalities except for sluggish relaxation of deep tendon reflexes.

Initial laboratory findings showed mild normocytic anemia and mild liver dysfunction. Urinalysis was negative. Urine volume ranged from 500 to $1200 \mathrm{ml}$ per day;

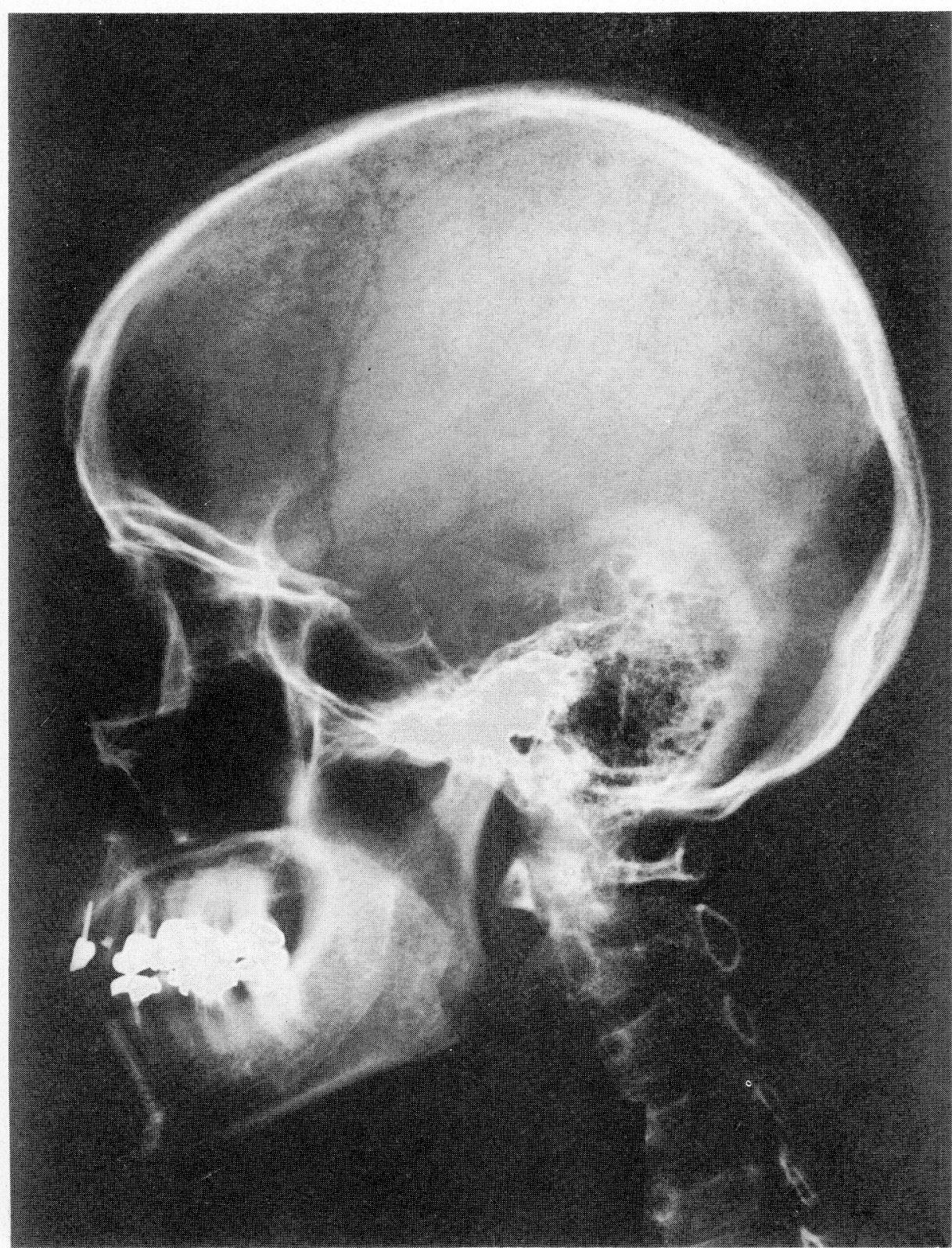

Fig. 2. Skull X-ray photo. The lateral view of the skull X-ray film shows a slightly enlarged sella and a double floor sign. 
the specific gravity of the urine was 1.022 . free T4, $0.25 \mathrm{ng} / 100 \mathrm{ml}$; and thyroid Serum sodium, potassium, calcium, and stimulating hormone (TSH), $1.7 \mu \mathrm{U} / \mathrm{ml}$ phosphate were within normal limits. The (measured by a sensitive immunoradiometric blood glucose level was $74 \mathrm{mg} / 100 \mathrm{ml}$. Serum C3 was $73.3 \mathrm{mg} / 100 \mathrm{ml}$, and C4 was $14.6 \mathrm{mg} / 100 \mathrm{ml}$. Study of peripheral $1 y \mathrm{~m}-$ phocytes revealed that OKT-4 was $56.4 \%$ and OKT-8 was $13.2 \%$, and that the T4/T8 ratio was high (4.305). Serum angiotensin converting enzyme was $15.7 \mathrm{IU} / \mathrm{L}$ and serum TPHA was negative. PPD was positive.

Serum thyroxine (T4) was $0.8 \mu \mathrm{g} / 100 \mathrm{ml}$; serum triiodothyronine (T3), $52 \mathrm{ng} / 100 \mathrm{ml}$; assay. The minimal detectable concentration was $0.025 \mu \mathrm{U} / \mathrm{ml}$, the normal range was 0.30 to $4.5 \mu \mathrm{U} / \mathrm{ml}$ ) (Mori et al., 1986). The thyroid $99 \mathrm{mTc}$-pertechnetate uptake was $0.5 \%$ (normal range : $0.4-2.5 \%$ ). Antithyroid antibodies were negative. The plasma cortisol concentration $(3.7 \mu \mathrm{g} / 100 \mathrm{ml})$ and 24 h-urinary excretion of $17-\mathrm{OHCS}$ $(1.0 \mathrm{mg} /$ day $)$ and $17-\mathrm{KS}(0.6 \mathrm{mg} /$ day $)$ were low.

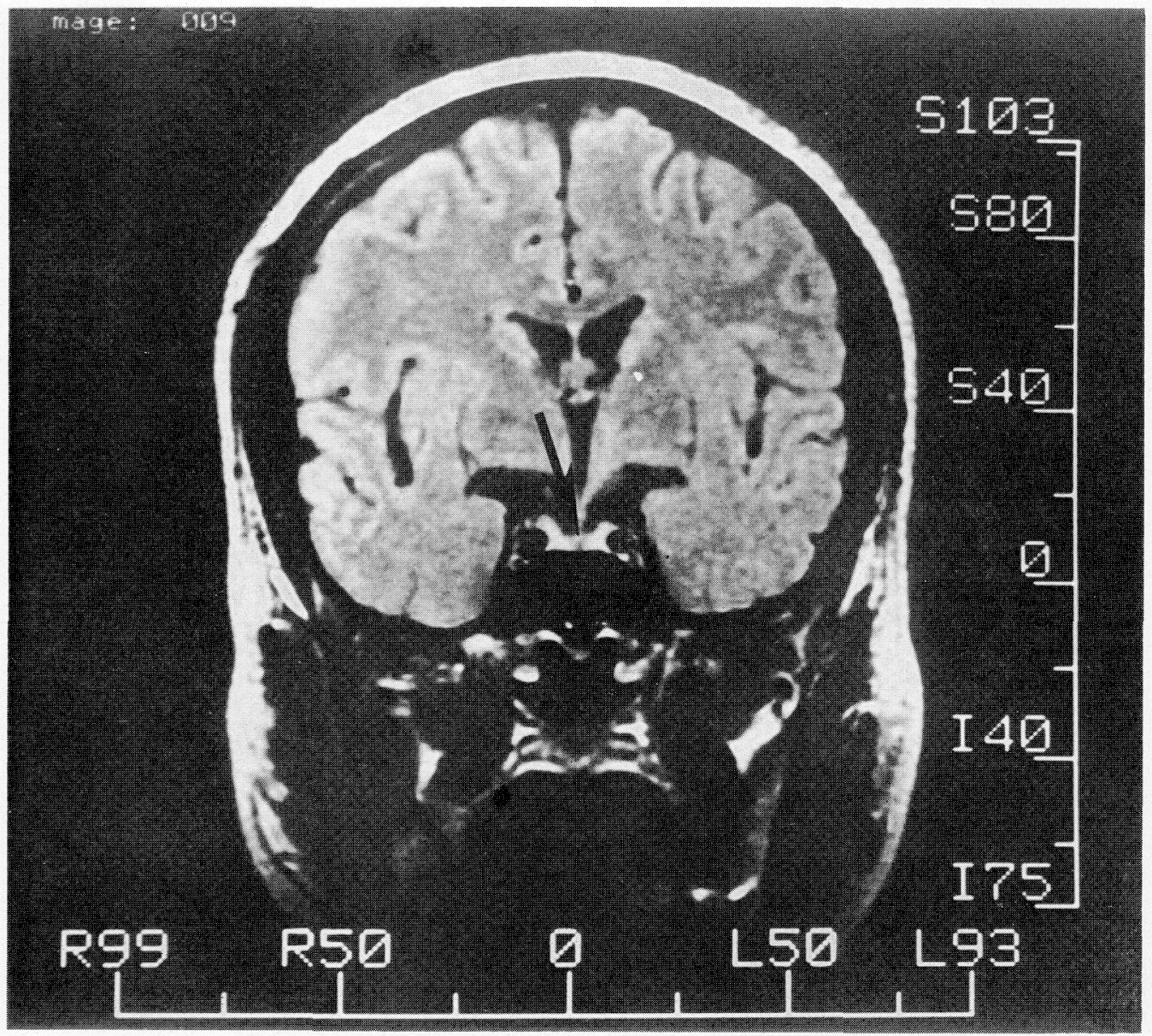

Fig. 3. A magnetic resonance image (MRI) of the pituitary region. MRI shows a low density mass of $5 \mathrm{~mm}$ in diameter (arrow) in the middle of the anterior pituitary lobe. 
Anterior pituitary functions are shown in Fig. 1. Plasma ACTH responses to CRF and insulin-induced hypoglycemia were blunted, although the plasma cortisol response to exogenous ACTH was normal. Plasma GH showed no response to insulininduced hypoglycemia or GRF. Serum gonadotropin (LH and $\mathrm{FSH}$ ) responses to LH-RH were blunted. Serum TSH showed a delayed and blunted response to TRH, not associated with any serum T3 increase and measured TSH was considered biologically inactive (Mori et al., 1986). Serum TSH did not respond to sulpiride. Serum prolactin showed almost no response to TRH or sulpiride. The diagnosis of panhypopituitarism was established.

Skull X-ray films revealed a slightly enlarged sella with double floor sign (Fig. 2). Magnetic resonance imaging (MRI) showed a low intensity mass ( $5 \mathrm{~mm}$ in diameter) in the middle of the anterior pituitary lobe (Fig. 3).

Pituitary microadenoma was suspected and transsphenoidal exploration of the sella was performed. When the dura was incised and opened, rather hard abnormal dullwhite pituitary tissue was observed. In the middle of the anterior lobe a grayish and fragile part was seen. Frozen section of the biopsy specimen revealed chronic inflammation; radical excision was not performed.

Histological examination of the excised specimen showed degenerated anterior pituitary tissue with moderate lymphocytic infiltration in a fibrous stroma (Fig. 4). No lymphoid follicles or germinal centers were observed. There were granulomatous lesions without infiltration with multinuclear giant cells. No caseous necrosis in the center of the granulomatous lesion or microorganism were detected. An immunohistochemical study using anti-BCG antigen demonstrated no positive findings in the lesion. The residual adenohypophyseal cells showed weak positive immunostaining for ACTH and TSH ; GH, LH, FSH, PRL, IgG, IgA and
IgM were negative in immunostaining.

Circulating antibody to pituitary gland, measured by indirect immunocytochemistry against frozen rat pituitary gland, was negative. HLA typing revealed A24(9), A26(10), B39(16), CW1 and DR4.

The postoperative course was uneventful. Anterior pituitary function tests were repeated but remained unchanged compared with the preoperative function tests. Nine months postoperatively, the patient's thyroid and corticosteroid replacement levels were satisfactory.

\section{Discussion}

The present case developed hypopituitarism of about 5 years duration and was diagnosed as having idiopathic hypopituitarism. She had a previous history of amenorrhea after delivery of her first child, which was not associated with massive bleeding. Sheehan's syndrome was considered to be unlikely because she could breast-feed the baby and had regular menses afterwards lasting for 17 years. A small mass lesion revealed by MRI led us to explore the pituitary fossa using the transsphenoidal approach. Histological examination of the biopsy specimen revealed the presence of granulomatous and lymphocytic infiltration with considerable destruction of the normal pituitary structure.

Granulomatous hypophysitis has occasionally been reported. Tuberculosis was in the past considered an important factor in the development of granulomatous lesions in the pituitary (Doniach and Wright, 1961; Rickards and Harvey, 1954). However, characteristic giant cells and/or anti-BCG positive staining were not seen in the present case. Most reported cases of tuberculous hypophysitis were associated with impaired posterior lobe function (Doniach and Wright, 1951; Rickards and Harvey, 1954; Kiaer and Norguard, 1969; Taylon and 


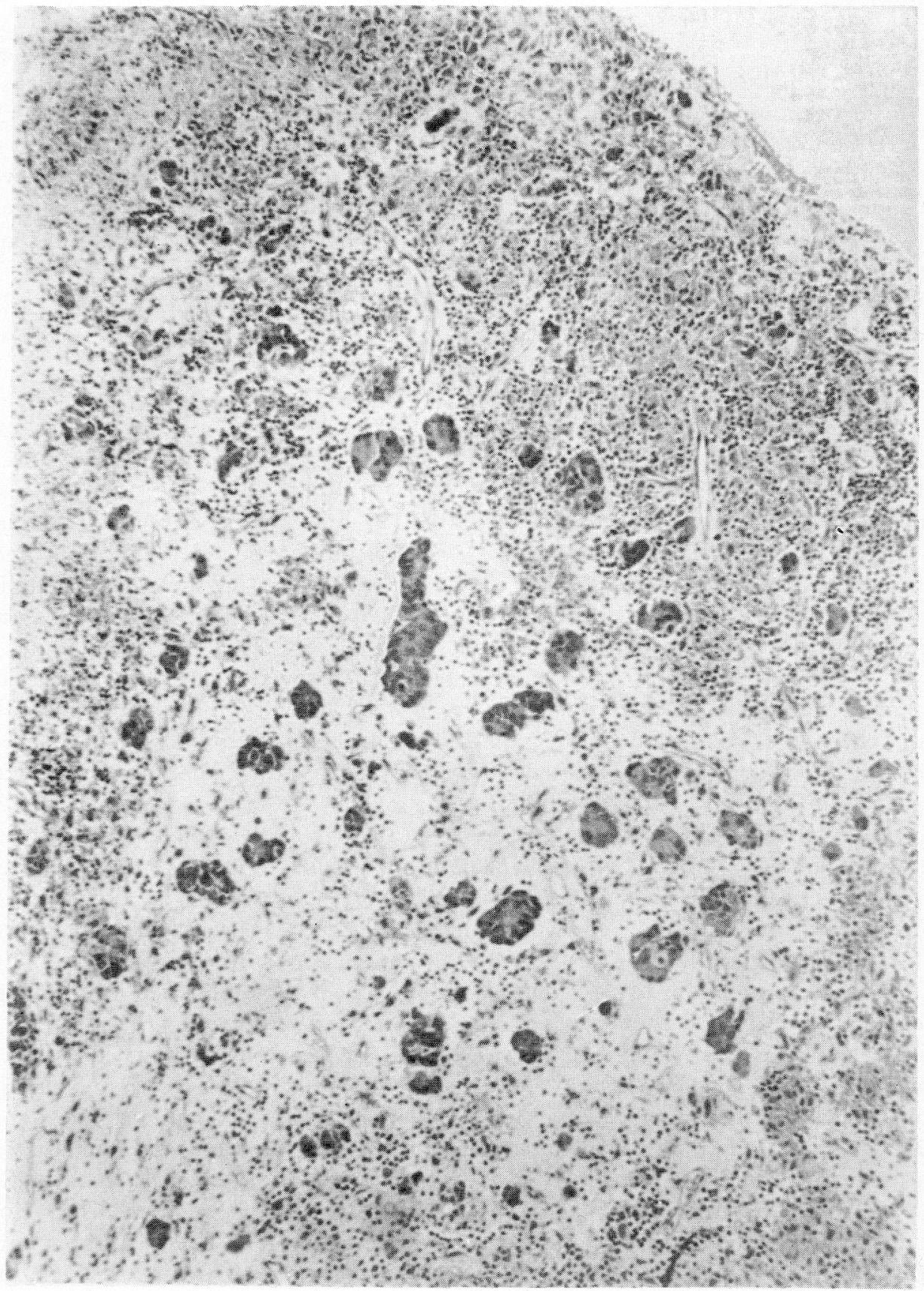

Fig. 4. Histological findings of the biopsied specimen of the anterior pituitary gland. Left: Degenerated pituitary gland with moderate lymphocytic infiltrations in the fibrous stroma. No lymphoid follicles or germinal centers are seen. 


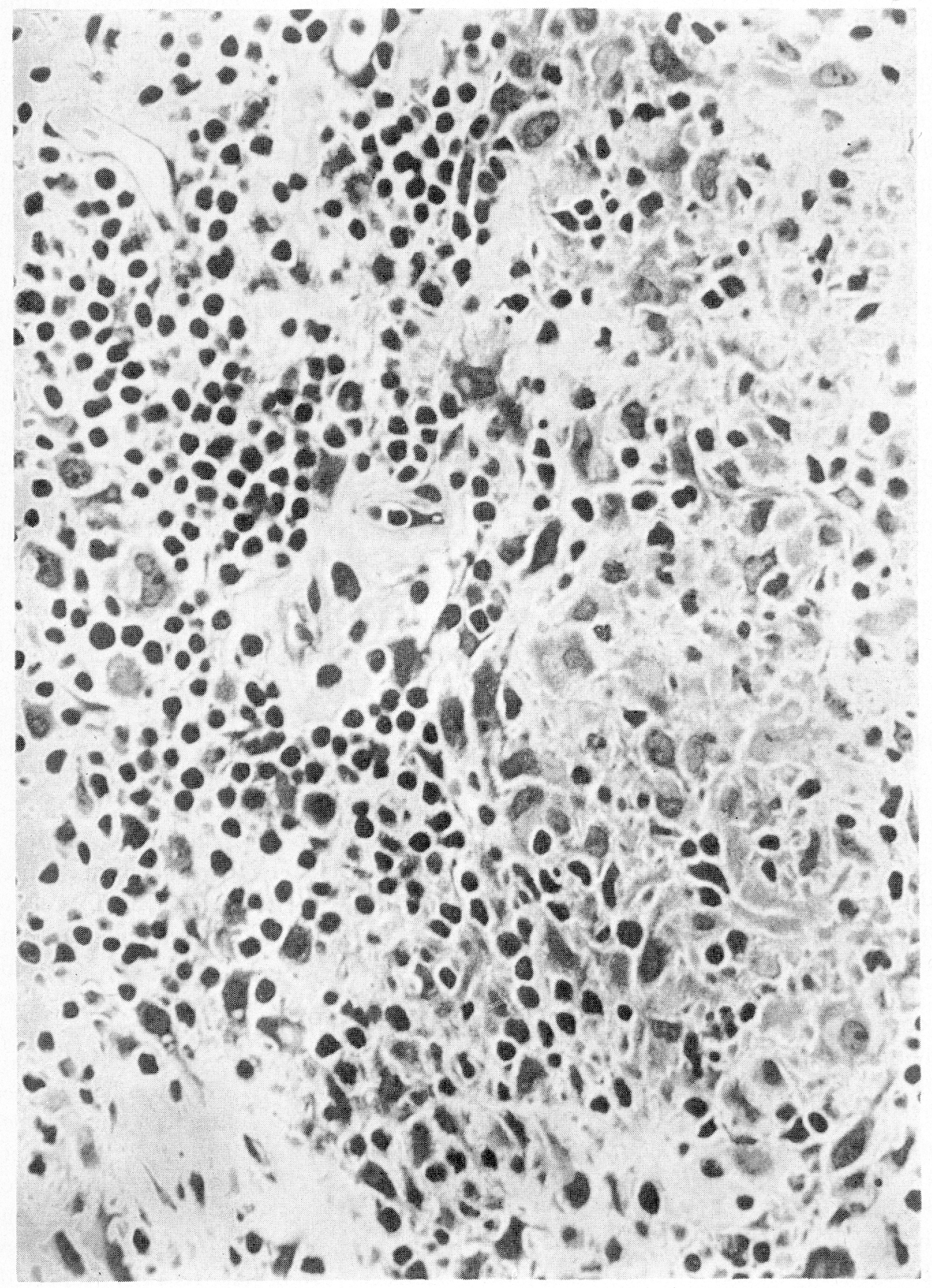

Right: Granulomatous lesions with no infiltration of multinuclear giant cells or caseous necrosis. 
Duff, 1980). However, even after steroid replacement, the patient's ability to concentrate urine was maintained. Syphilis, sarcoidosis and infections resulting from other microorganisms were also considered unlikely. Until now, there have been approximately 20 reported cases of granulomatous hypophysitis of unknown origin (Kiaer and Norguard, 1969; Jose Manuel del Poze et al., 1980 ; Taylon and Duff, 1980 ; Hassoun et al., 1985). The present case should be classified in this category, even though the lack of giant cell formation and posterior lobe dysfunction make the present case somewhat different from the reported cases.

Lymphocytic adenohypophysitis is also quite rare; to our knowledge, 20 cases have been reported (Goudie and Pinkerton, 1962; Hume and Roberts, 1967; Egloff et al., 1969 ; Lack, 1975 ; Gleason et al., 1978; Richtsmeier et al., 1980; Mayfield et al., 1980 ; Asa et al., 1981; Quencer, 1980; Portocarrero et al., 1981; Cebelin et al., 1981 ; Hungerford et al., 1982; Baskin et al., 1982; Mazzone et al., 1983; Madsen et al., 1985; Sobrinho-Simoes et al., 1985, Jensen et al., 1986; Wild and Kepley, 1986). Nine cases were diagnosed by autopsy, and 11 cases by biopsy. These biopsies were performed due to ballooning of the sella turcica, and signs and symptoms of a pituitary mass lesion. CT and MRI in the present case failed to show apparent enlargement of the sellar content or the existence of a microadenoma-like mass, but X-ray film showed a double floor sign. Interestingly, 14 of the 19 previously reported cases had had their disease onset during pregnancy or the postpartum period. Histopathologically, they showed massive lymphocytic infiltrations with lymphoid follicles and germinal centers, characteristic of autoimmune inflammation. Destructive autoimmune thyroiditis and exacerbations of systemic lupus erythematosus in the postpartum period are commonly associated. Amenorrhea following delivery, together with abnormal radiological findings, may be indicative of lymphocytic adenohypophysitis in the present case. Of the reported cases which underwent autopsy, most died approximately one year after the onset of the disease. In contrast to them, the present case has several unique features: 1) no lymphoid follicles or germinal centers were present; 2) regular menstrual cycles resumed after a 5 year duration of amenorrhea and continued for 17 years until clinical manifestations of hypopituitarism appeared; 3 ) even after the onset of clincal manifestations, the disease progressed slowly; 4) remarkable granulomatous changes were coexistent. No antipituitary, antithyroid or other nonorgan specific antibodies were detected, but decreased serum complement concentrations and an elevated ratio of OKT4/OKT8 in peripheral lymphocytes suggest possible autoimmune abnormalities. The present case may have had a mild lymphocytic adenohypophysitis during the postpartum period, but fortunately recovered from it and was able to live a natural life for 17 years. Hume and Reberts (1967) reported a case of lymphocytic adenohypophysitis without germinal centers in a 74-year-old woman. Lymphocytic adenohypophysitis may predominantly affect young women in relation to pregnancy or delivery. Mild cases may be able to survive at this stage. In the present case, gradual progression of granulomatous inflammation may have taken place and finally led to an overt panhypopituitary state. Pituitary hormone deficiencies, especially ACTH deficiency, seem to be critical for prognosis, and in the present case, impaired but considerable secretory reserves of ACTH and TSH were observed through function tests and immunohistochemistry. McKeel (1983) has recently reported that both granulomatous and lymphocytic hypophysitis have common ultrastructural features and possibly represent different stages of a single disease. The present case lends support to his proposal. 


\section{References}

Asa, S. L., J. M. Bilbao, K. Kovacs, R. B. Josse and K. Kreines (1981). Lymphocytic hypophysitis of pregnancy resulting in hypopituitarism: a distinct clinicopathologic entity. Ann. Int. Med. 95, 166-171.

Baskin, D. S., J. J. Townsend and C. B. Wilson (1982). Lymphocytic adenohypophysitis of pregnancy simulating a pituitary adenoma: a distinct pathological entity. report of two cases. J. Neurosurg. 56, 148-1532.

Cebelin, M. S., M. E. Velasco, J. M. de las Mulas and R. L. Druet (1982). Galactorrhea associated with lymphocytic adenohypophysitis. Br. J. Obstet. Gynecol. 88, 675-680.

Doniach, I. and E. A. Wright (I951). Two cases of giant-cell granuloma of the pituitary gland. J. Pathol. Bacteriol. 63, 69-793.

Egloff, B., W. Fischbocher and E. Goumoens (1969). Lymphomatose Hypophysitis mit Hypophyseninsuffizienz. Schweiz. Med. Wschr. 99, 1499-15024.

Gleason, T. H., P. L. Stebbins and M. F. Schanahan (1978). Lymphoid hypophysitis in a patient with hypoglycemic episodes. Arch. Path. Lab. Med. 102, 46-485.

Goudie, R. B. and P. H. Pinkerton (1962). Anterior hypophysitis and Hashimoto's disease in a young woman. J. Path. Bact. 83, 584586.

Hassoun, P., E. Anayssi and I. Salti (1985). A case of granulomatous hypophysitis with hypopituitarism and minimal pituitary enlargement. J. Neurol. Neurosurg. Psychiat. 48, 949-951.

Hume, R. and G. H. Roberts (1967). Hypophysitis and Hypopituitarism: Report of a case. Brit. Med. J. 2, 548-550.

Hungerford, G. D., P. J. Biggs, J. H. Levine, Shelley Jr. B. E., P. L. Perut and J. K. Chambers (1982). Lymphoid adenohypophysitis with radiologic and clinical findings resembling a pituitary tumor. $A . J . N . R .3,444-$ 446.

Jensen, M. D., B. S. Handwerger, B. W. Sheithauer, P. C. Carpenter, R. Mirakian and

P. M. Banks (1986). Lymphocytic hypophysitis with isolated corticotropin deficiency. Ann. Int. Med. 105, 200-201.

Jose Manuel del Pozo, J., J. Enrique Roda, J.
G. Montoya, J. R. Iglesias and A. Hurtado (1980). Intrasellar granuloma. J. Neurosurg. 53, 717-719.

Kiaer, W. and J. O. R. Norguard (1969). Granulomatus hypophysitis and thyroiditis with lymphocytic adrenalitis. Acta. Path. Microbiol. Scand. 76, 229-238.

Lack, E. E. (1975). Lymphoid "hypophysitis" with end organ insufficiency. Arch. Path. 99, 215-219.

Madsen, F. F., O. Dohr and E. Ludwingsen (1985). Lymphocytic adenohypophysitis: a review and a case. Dan. Med. Bull. 32, 185188.

Mayfield, R. K., J. H. Levine, L. Gordon, L. Powers, R. M. Galbraith and S. E. Rawe (1980). Lymphoid adenohypophysitis presenting as a pituitary tumor. Am. J. Med. 69, 619-623.

Mazzone, T., W. Kelly and J. Ensinck (1983). Lymphocytic hypophysitis: associated with antiparietal cell antibodies and vitamin B12 deficiency. Arch. Int. Med. 143, 1794-1795.

McKeel, D. W. (1983). Common histopathologic and ultrastructural features in granulomatous and lymphoid adenohypophysitis. Program of the 65th annual meeting of the Endocrine Society, San Antonio, Texas, 437. (Abstract).

Mori, T., K. Hirano, S. Kosugi, M. Miyamoto, H. Sugawa, T. Akamizu, H. Nakamura and H. Imura (1986). Fundamental and clinical studies on sensitive TSH IRMA "TSH RIABEAD II" kit. Clin. Endocrinol. (Tokyo). 34, 859-868.

Portocarrero, C. J., A. G. Robinson, A. L. Taylor and I, Klein (1981) Lymphoid hypophysitis: an unusual cause of hyperprolactinemia and enlarged sella turcica. J. A. M. A. 246, 1811-1812.

Quencer, R. M. ([980). Lymphocytic adenohypophysitis: autoimmune disorder of the pituitary gland. A. J. N.R. 1, 343-345.

Richtsmeier, A. J., R. A. Henry, J. M. B. Bloodworth and E. N. Ehrlich (1980). Lymphoid hypophysitis with selective adrenocorticotrophic hormone deficiency. Arch. Int. Med. 140, 1243-1245.

Rickards, A. G. and P. W. Harvey (1954). Giant-cell granuloma and the other pituitary granulomata. Quart. J. of. Med., New series XXIII. 92, 425-440.

Sobrinho-Simoes. M., A. Brandao, M. E. Paiva, B. Vilela, E. Fernandes and F. CarneiroChaves (1985). Lymphoid hypophysitis in a 
patient with lymphoid thyroiditis, lymphoid adrenalitis, and idiopathic retroperitoneal fibrosis. Arch. Path. Lab. Med. 109, 230-233. Taylon, C. and T. A. Duff (1980). Giant-cell granuloma involving the pituitary gland. $J$.
Neurosurg. 52, 584-587.

Wild, R. A. and M. Kepley (1986). Lymphocytic hypophysitis in a patient with amenorrhea and hyperprolactinemia: a case report. $J$. Reproductive Medicine 31, 211-216. 